\title{
Introduction of Web based Continuous Professional Development to Sri Lanka
}

\author{
Dr. Gumindu G.A.K. Kulatunga, MBBS PG Cert.Med,Edu. \\ Msc Student in Bio-Medical Informatics, Post Graduate Institute of Medicine, University of Colombo, Sri Lanka \\ E-Mail address: gumindu@ gmail.com
}

Dr. Rohana B. Marasinghe, MBBS, MPhil,PhD

Senior Lecturer, Department of Medical Education and Health Sciences, Faculty of Medical Sciences, University of Sri Jayewardenepura, Gangodawila, Nugegoda, Sri Lanka

E-Mail address: rohanabm@yahoo.com

Dr. Indika M Karunathilake, MBBS, CTHE, MC(UK)

Senior Lecturer in Medical Education, Faculty of Medicine, University of Colombo

Director, Medical Education Development and Research Centre, (MEDARC)

E-Mail address: karunathilake@hotmail.com

Prof. Vajira H.W. Dissanayake, MBBS, $\mathrm{PhD}$

Professor, Department of Anatomy, and Human Genetics Unit, Faculty of Medicine, University of Colombo, Sri

Lanka

E-Mail address: vajirahwd@hotmail.com

Sri Lanka Journal of Bio-Medical Informatics 2012;3(4):127-131

doi: http://dx.doi.org/10.4038/sljbmi.v3i1.4798

\begin{abstract}
Continuous Professional Development (CPD) can be described as a continuous process which begins on the day a person start practicing as a doctor. Continuous Medical Education (CME) concentrates on improving individual professional knowledge by education and training in areas determined by experts. But in CPD, professionals play an active role in defining the knowledge which they see as relevant to their own professional needs and learning takes place not only at individual level but also at organisational level. CPD is becoming a popular mode of learning worldwide by which doctors keep their practice up to-date. CPD is seen as essential for effective practice and for professional development. Even though the standard format of CPD for many years has been formal, there is no specific method in operation. Over the last decade there has been increasing interest in the use of computers to facilitate collaborative learning between healthcare professionals for CPD. Web-based learning is an attractive methodology for medical education and offers some advantages over traditional methods. There is improved clinical practice and improved clinical decision making as a result of web based learning. Professionals are satisfied with the flexibility and the convenience offered in Web-based mode of CPD delivery as it saves time and money. Web based CPD programmes will fulfil the educational requirements of health professionals in the peripheral parts of Sri Lanka who have difficulty in attending formal education sessions due to their geographical isolation. Meeting the educational needs of professionals already in practice remains a challenge and web based online CPD can play a major role in proving the high demand.
\end{abstract}

Keywords - CPD; CME; e-learning; Information Communication Technology 


\section{What is CPD?}

Continuous Professional Development (CPD) refers to the education of physicians following completion of formal training, which will help to maintain, develop or increase knowledge, technical skills and standards, resulting in better healthcare.

The spectrum of CPD is broad which include not only acquiring new knowledge or skills as a doctor but also encompass one's personal development ${ }^{(6)}$. Studies have demonstrated that there is no designated method of $\mathrm{CPD}^{(12)}$.

\section{The difference between CME and CPD}

CME concentrates on professionals keeping them upto date. CME focuses on improving specialist knowledge by education and training in areas determined by experts. In CPD, professionals play an active role in defining the knowledge which they see as relevant to their own professional needs. Learning takes place not only at individual level, but also at the organisational level $^{(1)}$. Due to these facts CPD is an active mode of education which addresses a broader spectrum of the medical profession.

\section{Importance of CPD for medical professionals}

The amount of biomedical knowledge available doubles every 20 years ${ }^{(13)}$. A doctor's practice could become rapidly outdated without activities that allow doctors to refresh current knowledge and skills. As needs of the patients, doctors and of the health service within which they practice keep changing with time, being up to date with these changes is necessary if a doctor is to engage in good medical care ${ }^{(5)}$.

CPD is becoming a popular mode of learning worldwide. Professional activity helps to maintain, develop or increase knowledge, problem solving, technical skills and professional performance standards with the aim that physicians can provide better healthcare ${ }^{(4)}$. Learning via CPD is seen as essential for effective practice and for individual professional development, whether or not it results in career progression ${ }^{(12)}$.

\section{Integration of ICT to deliver CPD programmes}

The standard format of CPD for many years has been formal study courses, conferences, symposiums or workshops. Doctors in developed countries perceive that CPD opportunities are mostly available to those who live in main cities. Due to difficulties with finances, time, job demands and work- life balance CPD programmes are inaccessible to most others ${ }^{(12)}$. Introduction of e-learning (which is defined as "learning facilitated and supported through the 
use of ICT) in recent history has revolutionised CPD programmes making it easily accessible even to doctors from rural areas.

Internet based CPD programmes across the world provide opportunities to deliver collaboration and social learning. CPD on the Internet has grown steadily over the past several years ${ }^{(3)}$. It has the potential to generate new knowledge and promotes higher achievement. Studies document that web based learning is an attractive methodology for medical education and offers some advantages over traditional methods ${ }^{(8)}$. Research has highlighted that professionals are satisfied with the flexibility and convenience offered in web-based distant education and it is an effective and efficient mode of CPD delivery, specially for technologically competent professionals ${ }^{(9)}$. Although e-learning is not universally accepted as a preferred learning style for all, it provides a potential method by which barriers such as lack of time and geographical isolation can be minimised. Some advantages of e-learning include: support for delivery by employers and the government, the choice of course can be based on content rather than geographic proximity, easy electronic access, potential daily contact with tutors and opportunities for cross cultural learning. Online CPD courses are possible due to developments in multimedia technology and the internet. Widespread use of the internet and new multimedia data communication technologies created the first generation of online CPD courses taught in virtual classrooms. The first online CPD course emerged in $1996^{(7,11)}$. Second generation courses include interfaces that allow user interactivity, allowing the experience to approximate the traditional 'live' lecture which is the current educational 'gold standard'. Current CPD will provide a mobile, interactive, tactile, online, virtual reality experience. Specifically, online CPD courses represent a cost effective, convenient option and one that affords physicians much flexibility when fulfilling credit requirements ${ }^{(7)}$. Furthermore studies assessing the effectiveness of CPD across domains are less effective. Interactive techniques are more effective than non-interactive ones and multiple exposures to the CME activity are more effective than single exposure ${ }^{(10)}$.

\section{The importance of web based CPD to Sri Lanka}

Medical Officers and Specialists in rural areas of Sri Lanka are at a disadvantage when accessing CPD programmes as their geographical isolation influences attendance at seminars, workshops and informal discussions with colleagues. Lack of access to Continuous professional education can have a significant influence on recruitment and retention of healthcare professionals in rural areas.

eLearning using web based distance education principles has expanded opportunities for the provision of a flexible, convenient and interactive form of CPD that has fulfilled the requirements of health professionals in peripheral parts of Sri Lanka who have difficulty attending formal education sessions. 


\section{Drawbacks of online web based CPD programmes}

Research has pinpointed several issues that may explain why medical professional are reluctant to use this valuable online resource ${ }^{(7)}$. Some of these include access problems, lack of interactivity, insufficient computer skills, and mistrust of e-commerce. Dissatisfaction in webbased study course is sometimes attributed to the frustration experienced by the learner due to technological issues ${ }^{(14)}$. Reasons for frustration may be related to the participants' lack of knowledge as well as technical issues ${ }^{(2)}$.

\section{Future}

Meeting the educational needs of medical professionals already in practice remains a challenge and web based online CPD can play a role in catering to the demand. Currently there are no Sri Lankan studies on the demand for online CPD. It is hoped that a study could be undertaken in the near future.

\section{References}

1. Brigley S, Young Y, Littlejohns P, McEwen J. Continuing education for medical professionals: a reflective model. Postgrad Med J. 1997 ; 73(855):23-6. doi: http://dx.doi.org/10.1136/pgmj.73.855.23

2. Collett D, Kanuka H, Blanchette J, Goodale C. Learning technologies in distance education. Edmonton: University of Alberta; 1999.

3. Curtis, A. Olson, Shershneva, Marianna B. Setting Quality Standards for Web-Based Continuing Medical Education. J Contin Educ Health Prof.2004; 24(2): 100-11. doi: http://dx.doi.org/10.1002/chp.1340240207

4. Davis N, Davis D, Bloch R. Continuing medical education: AMEE Education Guide No 35. Med Teach. 2008 ; 30(7):652-66.

doi: http://dx.doi.org/10.1080/01421590802108323

5. Epa SS. CPD Certification of Sri Lankan doctors. Ceylon Med J. 2005 ; 50(2):76-8.

6. Epa SS. National CPD certificate: Information and Guidance Book. Colombo: Sri Lanka Medical Association; 2010.

7. Gandsas A, McIntireet K. Internet and continuing medical education. Min Invas Ther \& Allied Technologies 2002; 11(2):49-54.

doi: http://dx.doi.org/10.1080/136457002753632457

8. Kadriye O, Baker RC. Teaching medical professionals online: A cross-discipline experience. Med Teach. 2010; 32:262-64. 
doi: http://dx.doi.org/10.3109/01421590903434185

9. Kanuka H, Nocente N. Exploring the effects of personality type on perceived satisfaction with web-based learning in continuing professional development. Distance Education. 2003; 24(2):227-44.

10. Marinopoulos S, Dorman T, Ratanawongsa N, Wilson LM, Ashar BH, et al. Effectiveness of continuing medical education. Evidence report /technology assessment 2007; 149: 1-69.

11. Peterson MW, Galvin JR, Dayton C, D'Alessandro MP. Realizing the promise: delivering pulmonary continuing medical education over the Internet. Chest. 1999 ; 115(5):1429-36.

12. Schostak J, Davis M, Hanson J, et al. Effectiveness of Continuing Professional Development project: A summary of findings. Med Teach. 2010;32(7):586-92.

doi: http://dx.doi.org/10.3109/0142159X.2010489129

13. Stewart, GD, Teoh KH, Pitts D, Garden OJ, Rowley DI. Continuing Professional Development for Surgeons. Surgeon.2008; 6(5): 288-92.

doi: http://dx.doi.org/10.1016/S1479-666X(08)80053-4

14. Swan K, Shea P, Frederickson E, Pickett A, Pelz W, Maher G. Building knowledge building communities: Consistency, contact and communication in the virtual classroom. Journal of Educational Computing Research. 2000; 23(4): 359-83. 